\title{
Rangeland Ecosystem Goods and Services: Values and Evaluation of Opportunities for Ranchers and Land Managers
}

\author{
By Kristie Maczko, John A. Tanaka, Robert Breckenridge, \\ Lori Hidinger, H. Theodore Heintz, William E. Fox, \\ Urs P. Kreuter, Clifford S. Duke, John E. Mitchell, \\ and Daniel W. McCollum
}

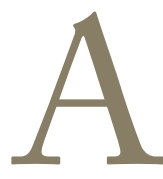

lthough the US Department of Agriculture's 2005 public commitment to use market-based incentives for environmental stewardship and cooperative conservation focused land managers' attention on the concept of ecosystem goods and services (EGS), this was not a new idea. Much earlier in the 20th century, Aldo Leopold embraced the value of open space, calling for preservation of New Mexico's Gila Wilderness Area and later urging Americans to espouse a "land ethic" that recognized the unique contributions of wildlands and agricultural landscapes to the American ethos. Theodore Roosevelt preserved millions of acres of the American West as national forests and monuments, to provide the greatest good for the greatest number of people with these reserves as a constant source of valuable production commodities-in today's jargon, ecosystem goods and services. ${ }^{1}$

While approaching benefits derived from natural rangeland systems in terms of goods and services is not a new idea, it has particular relevance now as populations become more urban and rangelands are threatened by subdivision, development, and alteration. Reconnecting people with the lands that provide the food, fiber, clean water, biofuels, cultural heritage, and recreation opportunities that they value, in terms of these benefits upon which they depend, is critical to mitigate threats to rangeland systems.

Alternative income sources for ecosystem services such as fee permits for hunting, fishing, hiking, bird watching, and rock collecting on private lands now help ranchers augment their income from livestock production. Although there is considerable debate about potential impacts of these traditional and emerging activities, research has documented that ranches are more effective than subdivisions or ranchettes at preserving intact rangeland ecosystems. ${ }^{2}$

At present, rangelands comprise approximately 770 million acres of the US land base. Over half of these rangelands are privately owned. ${ }^{3}$ Public and private land ranchers and the rangeland resources they manage provide commodity, amenity, and spiritual values ${ }^{4}$ that are vital to the well-being of ranching operations, the communities in which they operate, and the nation as a whole. As society attempts to satisfy multiple demands with limited resources, availability of quantified data about stocks and supplies of rangeland ecosystem services to serve as a basis for rancher decision-making also becomes more important.

Expanding ranch operations to manage for multiple goods and services beyond traditional cattle production can increase income and conservation goals to benefit ranchers and communities. Projections predict that grazing land use for wildlife habitat, as well as wildlife-related human activities, will increase during the next half century. ${ }^{5}$ Ranchers might be able to diversify their income and net worth by managing to enhance wildlife abundance and diversity, or maintaining habitat for rare plants. Nature enthusiasts, bird watchers, and amateur botanists might pay to visit ranches and engage in a variety of recreational pursuits. ${ }^{6-8}$ Maintaining healthy, functional populations of assorted rangeland species can also provide profitable income streams for ranch families.

With these benefits in mind, the Sustainable Rangelands Roundtable (SRR) convened a special workshop to consider these issues in the context of rangeland sustainability. The SRR is an open partnership of rangeland scientists, ecologists, economists, sociologists, environmental advocates, industry representatives, agency staff, and academicians. This organization has a 10-year history of emphasizing development of rangeland monitoring metrics and promoting dialogue on aspects of rangelands sustainability. ${ }^{9}$

The SRR ecosystem services workshop sought to explore goods and services produced by rangeland ecosystems, as well as ways to categorize, measure, and explore linkages among goods and services and associated socioeconomic 


\begin{tabular}{|c|c|c|c|}
\hline $\begin{array}{l}\text { Type of related } \\
\text { ecological process }\end{array}$ & $\begin{array}{c}\text { Tangible } \\
\text { extracted goods }\end{array}$ & $\begin{array}{l}\text { Tangible in situ services } \\
\text { (and disservices) }\end{array}$ & $\begin{array}{l}\text { Intangible in situ services } \\
\text { (primarily perceptual) }\end{array}$ \\
\hline $\begin{array}{l}\text { Primarily biologic } \\
\text { processes }\end{array}$ & $\begin{array}{l}\text { Food for human } \\
\text { consumption } \\
\text { Food for livestock } \\
\text { consumption } \\
\text { Fiber } \\
\text { Biofuels, feedstocks } \\
\text { Fish and wildlife to } \\
\text { catch and hunt } \\
\text { Biochemicals } \\
\text { Germ plasm }\end{array}$ & $\begin{array}{l}\text { Ecologically transmitted diseases } \\
\text { Ecologically transmitted pests }\end{array}$ & Wildlife and habitats to observe \\
\hline $\begin{array}{l}\text { Primarily hydrologic } \\
\text { processes }\end{array}$ & $\begin{array}{l}\text { Water for household use } \\
\text { Water for human use in } \\
\text { economic production }\end{array}$ & Floods affecting humans & $\begin{array}{l}\text { Water bodies for recreation and } \\
\text { tourism }\end{array}$ \\
\hline $\begin{array}{l}\text { Primarily atmospheric } \\
\text { processes }\end{array}$ & & $\begin{array}{l}\text { Air humans breathe } \\
\text { Air temperature and humidity } \\
\text { Precipitation on humans }\end{array}$ & \\
\hline Multiple processes & $\begin{array}{l}\text { Ornamental resources } \\
\text { Ceremonial items }\end{array}$ & & $\begin{array}{l}\text { Views and scenes to observe } \\
\text { Culturally or spiritually significant } \\
\text { sites to observe } \\
\text { Historically or archeologically } \\
\text { significant sites to observe } \\
\text { Sites/areas for recreation } \\
\text { and tourism } \\
\text { Scientifically significant } \\
\text { sites to observe }\end{array}$ \\
\hline \multicolumn{4}{|l|}{ Physical processes } \\
\hline Geologic & Minerals & $\begin{array}{l}\text { Earth movements and volcanic } \\
\text { eruptions affecting humans }\end{array}$ & \\
\hline Atmospheric & Wind energy & $\begin{array}{l}\text { Wind directly affecting humans } \\
\text { Atmospherically transported } \\
\text { chemicals and particulates }\end{array}$ & \\
\hline Hydrologic & Hydropower & & \\
\hline Miscellaneous & Solar energy & Insolation for human tanning & \\
\hline
\end{tabular}

elements. In keeping with the SRR emphasis on the importance of rangeland resources to meet society's current and future needs through sustainable management, consideration of rangelands within an ecosystem services framework can accentuate rangeland resource contributions to human wellbeing. Forty-seven participants came from 14 states, nine agencies, 10 universities, and nine nongovernmental organizations to develop information pertaining to rangeland ecosystem services. Products included partial lists of rangeland core ecological processes, goods, and services and more explicit acknowledgment of these entities in SRR's conceptual framework. ${ }^{10}$ Subsequent SRR work has focused on the use of monitoring indicators to quantify rangeland EGS, effects of alternative energy development on EGS, and potential management adaptations for EGS in the face of predicted climate change conditions.

Workshop participants identified many rangeland EGS and recognized the underlying ecological processes that provide them. Goods and services are classified here (Table 1) as ecosystem goods, tangible and intangible ecosystem services, and core processes, incorporating elements of several categorization systems suggested by participants at the workshop. ${ }^{11}$ This classification is designed to be internally consistent, as well as generally compatible, with the structure of the SRR Criteria and Indicators $(\mathrm{C} \& \mathrm{I})^{9}$ and the SRR Integrated Social, Ecological, and Economic Concept (ISEEC). ${ }^{10}$ The ISEEC framework was developed by SRR to illustrate linkages between ecological and socioeconomic factors affecting rangeland sustainability, with rangeland EGS providing the key linkage between these two domains (Fig. 1). The SRR ISEEC framework highlights the importance of ecosystem goods and services as the bridge across which ecological systems support socioeconomic needs and wants, as well as the feedback for the effects of these needs and wants on natural systems. The downward-pointing 


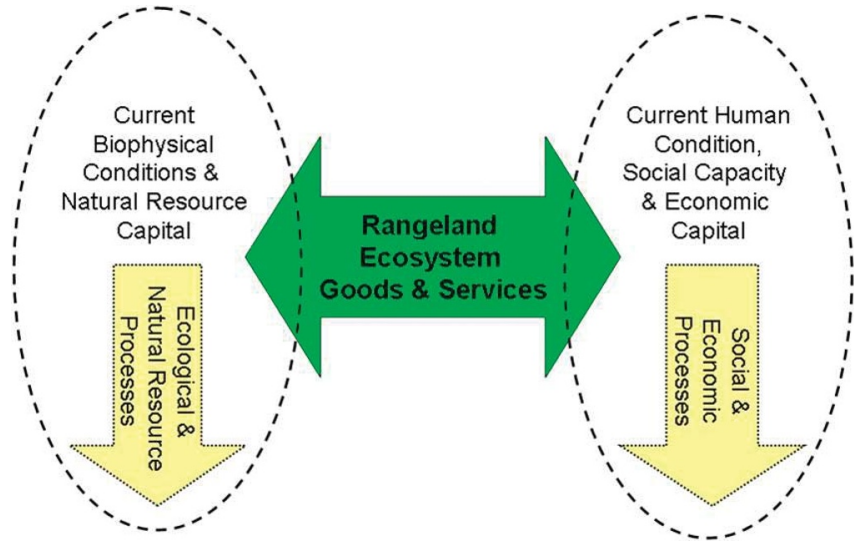

Figure 1. Rangeland ecosystem goods and services provide the linkage between socioeconomic and ecological domains.

arrows depict changing conditions and progress forward through time.

\section{SRR Rangeland EGS Terminology}

Rangeland EGS are elements or processes that yield benefits to humans. These benefits arise through satisfaction of human needs and wants, and as a result of such benefits, EGS have value. The most important and generally agreed upon categories identified by SRR rangeland EGS participant discussions as the basis for a categorization system (Table 1) are described as:

- rangeland ecosystem goods,

- rangeland ecosystem services, and

- core rangeland ecosystem processes.

Rangeland ecosystem goods are tangible outputs from ecosystems, made available to humans through human activities, beginning with extraction. Once outputs enter the economic system, they are transported, and usually transformed or combined with other goods and services to yield things of value to humans. Food and fiber are common examples of rangeland goods. Social and economic processes needed for extraction and subsequent processing and use of rangeland ecosystem goods are structured by our legal, institutional, and economic frameworks, particularly those affecting markets for such goods and the products to which they contribute.

Rangeland ecosystem services can be intangible or tangible, but their value to humans results from direct experiences in situ, or in place, where they are produced on rangelands, rather than through extraction and processing elsewhere. Tangible services are direct interactions with ecosystems that occur in situ, e.g., breathing air or being exposed to air temperatures or wind. Intangible services yield value to humans through experiences that are primarily perceptual, such as visual or kinesthetic experiences, rather than organic, such as eating or breathing. Viewing a scenic landscape would be an example of an intangible service.
Humans also can receive negative values from EGS, resulting in damages or costs rather than benefits. Negatively valued EGS (or disservices) are mostly tangible and arise from direct experiences that are negatively valued by those people who experience them. Examples range from being bitten by a mosquito to having a home burned by wildfire. The Millennium Ecosystem Assessment ${ }^{12}$ includes such negative services in the Regulating Services category, to emphasize healthy ecosystems' tendency to limit their damaging effects to humans. The categorization of EGS in Table 1 was designed to be value-neutral to avoid implying that it is easy to measure the extent to which healthy ecosystems mitigate damages through unaltered natural regulation.

Core ecological processes are the fundamental processes that occur in rangeland ecosystems through which life is sustained and through which all EGS are produced. Most EGS result from complex interactions among these processes. Almost all core ecosystem processes contribute to numerous categories of goods and services.

The terms for the EGS in Table 1 have been chosen to convey their use by, or effect on, humans rather than their desirable characteristics such as quality, quantity, location, and timing. For example, the list includes "water for household use" rather than "clean water." Such characteristics have strong effects on value, but require careful discussion to assure a consistent treatment across the full range of EGS.

Previously, EGS have been labeled in the literature according to human activity, experience, or assigned value. Table 1 makes explicit the activity or experience, but it avoids use of the term "value" in listing an EGS. Value is an attribute of human experience, not of ecosystems. There is a close relationship between characteristics of sites or areas and the type and value of experiences people have there. It is a challenge to itemize all characteristics that people might value and devalue. For example, we might drive long distances to enjoy a beautiful vista, but en route be irritated to see human developments on a landscape that was formerly undeveloped.

\section{Values of Rangeland Ecosystem Services and Potential for Conservation Incentives}

Ecosystem goods and services have value because they increase or decrease the satisfaction of human needs. Value arises from human interactions with EGS and can be positive or negative; they are personal and subjective. Values people place on EGS are closely related to the preferences revealed by choices they make. Value can be signaled by prices in market transactions or revealed by other methods. Using prices derived from market transactions for goods and services is part of the economic system's means of creating incentives that shape economic behavior. The higher the price, as a proxy for value, the more companies will produce and the less consumers will buy.

Values revealed or expressed through nonmarket processes also influence behavior. In general, allocation of resources to 
production of goods and services through collective action is less dynamic and often less efficient than those allocated by individuals. Such goods and services tend to be underproduced, because of their public goods nature.

Value can result from exchange of ownership, maintenance of the option for future use, the desire to make something available to future generations, or the mere existence of the good or service. The first is generally more amenable to market transactions and uses multiple regression techniques or travel cost methods to assign value to different characteristics. Option, bequest, and existence (i.e., nonmarket) values are not subject to transactions but have value nonetheless. These types of nonmarket values can be estimated by contingent valuation where respondents are asked what they would be "willing to pay." For example, a survey respondent might be asked to select the highest dollar amount that they would be willing to pay for the possibility of viewing grazing antelope on open range. When combined with many such responses, an estimate of the value for viewing antelope can be derived. Economists are mixed on how comparable these values are with real market-derived values.

In principle, all EGS values are derived from ecological processes that also have value, although in many cases that value will not be discernable through market prices. Because so many ecological processes interact to produce rangeland EGS, it is more difficult to estimate the value of an individual process.

However, valuation is critical to development of ecosystem services markets and use of EGS as a basis for alternative income streams and enterprise diversification for ranchers. To that end, SRR has developed a preliminary questionbased framework to help ranchers consider their ranching operation's potential to generate additional income from less traditional ecosystem services-based enterprises.

\section{Evaluating EGS as Alternative Income Sources}

EGS are as varied as their importance is to different users. To address this importance, SRR proposed a consistent set of questions to evaluate each good or service. Although responses to the questions are important, it is the evaluation and discussion process that provides the most useful information. Using a hypothetical example of a private landowner consulting with a certified rangeland management consultant, we will illustrate how these questions can be used to inform a landowner's EGS decisions.

Consider a 2,000-acre ranch with a commensurate public land grazing allotment. Several streams run through the ranch, which also has some stock water ponds and many developed and undeveloped springs. The ranch sits in the foothills of the Rocky Mountains. The country is wide open with picturesque views, an hour's drive out of a small city. More people are discovering the area for outdoor recreationhunting, fishing, off-highway vehicle use, bird watching, etc.

The ranch is a mosaic of sagebrush-dominated rangelands with native and introduced grasses in the understory.
Table 2. The Sustainable Rangelands Roundtable question-based framework to consider ecosystem goods and services in a ranching operation

Must Haves (yes/no)

Does the ecosystem good and service (EGS) exist on or is derived from rangelands?

Is the EGS important to rangeland ecosystem processes and/or human well-being?

Both questions must be answered "yes" to continue.

Wants (high/medium/low/NA)

High importance

Does the EGS provide a basic human need?

Is it important to society?

What is the current level of demand for the EGS?

How responsive is the EGS to management?

Moderate importance

How easily is the EGS measured?

How important is the EGS over local,

regional, and national spatial scales?

How important is the EGS over

different temporal scales?

How resilient is the EGS?

How much does human activity impact the EGS?

How important are rangelands to this EGS?

How unique is the EGS to rangelands?

Low importance

For this good, are there no potential substitutes?

Consequences

Is the EGS impacted by local, state,

or federal regulations?

Lowlands are used for hay production and a public land grazing permit is used to graze cattle for much of the spring and summer. Recently, there has been pressure to adjust cattle management on public lands away from springtime use due to conflicting resource concerns. The rancher worries about several issues that will affect the EGS that his land can produce. Table 1 provides a list of different potential EGS that could be considered and there might be more. Each of these EGS could be considered by the rancher for focused management and development as part of a business planning process.

This rancher, in visiting with the rangeland management consultant, looks at each EGS as a potential income source or as an opportunity to enhance conservation. During the discussion, it becomes apparent that a more rigorous way to evaluate the potential income sources is needed. The rancher and consultant agree upon a set of questions to frame the evaluation process. These questions are divided by the relative importance placed on the answer (Table 2). Table 3 provides an example of a completed worksheet for evaluating the different types of EGS (e.g., biological, atmospheric, hydrological). 
Table 3. Example responses for biofuels and other ecosystem goods and services (EGS) on the hypothetical ranch

\begin{tabular}{|c|c|c|c|c|}
\hline & $\begin{array}{l}\text { Domestic } \\
\text { livestock } \\
\text { for human } \\
\text { consumption }\end{array}$ & $\begin{array}{l}\text { Biofuel } \\
\text { feedstocks }\end{array}$ & $\begin{array}{c}\text { Fishing, } \\
\text { hunting, } \\
\text { and viewing } \\
\text { wildlife }\end{array}$ & $\begin{array}{l}\text { Recreation } \\
\text { and tourism } \\
\text { sites }\end{array}$ \\
\hline \multicolumn{5}{|l|}{ Must Haves (yes/no) } \\
\hline Does the EGS exist on or is it derived from rangelands? & Yes & Yes & Yes & Yes \\
\hline $\begin{array}{l}\text { Is the EGS important to rangeland ecosystem processes } \\
\text { and/or human well-being? }\end{array}$ & Yes & Yes & Yes & Yes \\
\hline \multicolumn{5}{|l|}{$\begin{array}{l}\text { For each column, both questions must be answered "yes" } \\
\text { to continue. }\end{array}$} \\
\hline \multicolumn{5}{|l|}{ Wants (high/medium/low/NA) } \\
\hline \multicolumn{5}{|l|}{ High importance } \\
\hline $\begin{array}{l}\text { Does the EGS provide a basic human need? Is it } \\
\text { important to society? }\end{array}$ & $\mathrm{H}$ & M & M & L-M \\
\hline What is the current level of demand for the EGS? & $\mathrm{H}$ & L-M & M & M \\
\hline How responsive is the EGS to management? & $\mathrm{H}$ & $\mathrm{H}$ & $\mathrm{H}$ & L \\
\hline \multicolumn{5}{|l|}{ Moderate importance } \\
\hline How easily is the EGS measured? & $\mathrm{H}$ & $\mathrm{H}$ & L & $\mathrm{H}$ \\
\hline \multicolumn{5}{|l|}{ How important is the EGS over different spatial scales? } \\
\hline Local & $\mathrm{H}$ & $\mathrm{H}$ & M & M \\
\hline Regional & M & M & L & L \\
\hline National & L & M & L & L \\
\hline How important is the EGS over different temporal scales? & M & M & M & L \\
\hline How resilient is the EGS? & M & L-M & $\mathrm{M}-\mathrm{H}$ & $\mathrm{H}$ \\
\hline How much does human activity impact the EGS? & $\mathrm{H}$ & M & H & L \\
\hline How important are rangelands to this EGS? & M & L & $\mathrm{M}-\mathrm{H}$ & $\mathrm{H}$ \\
\hline How unique is the EGS to rangelands? & M & L & $\mathrm{M}-\mathrm{H}$ & M \\
\hline \multicolumn{5}{|l|}{ Low importance } \\
\hline For this good, are there no potential substitutes? & L & L & M & L \\
\hline \multicolumn{5}{|l|}{ Consequences } \\
\hline Is the EGS impacted by local, state, or federal regulations? & L-M & L & $\mathrm{M}-\mathrm{H}$ & L \\
\hline
\end{tabular}

The first two questions (Must Haves) are meant to determine whether the EGS is rangeland-related and whether it is a good or service about which society cares. If the answer to both of these questions is "yes," the second set of questions (Wants) then evaluates the potential goods and services. The second set of questions is qualitatively evaluated as ranking high, medium, or low. These rankings are conceptualized as subjective importance levels, reflecting whatever values the user wants them to represent. Questions with a high ranking could be considered to offer good prospects, those with a medium ranking are less definitive, and those ranked low would indicate the bottom end of the continuum and be less likely to be successful. The fuzzy bounds of these ranking categories reflect the qualitative nature of the analysis. Again, the value of this process is more in the discussion and consideration of options rather than in a rigid ranking framework.
Following is a discussion of how the rancher and rangeland management consultant could use each question to evaluate one rangeland ecosystem good-biofuel. For additional information on rangeland ecosystem goods and services, please see "Sustainable Rangelands Ecosystem Goods and Services.",

We will assume that the rancher is considering converting a significant portion of native rangeland to biofuels feedstock production. In this case, in-depth discussions of trade-offs are necessary to understand the implications of this decision in terms of impacts to other EGS produced on the ranch.

The "Must Have" questions can be answered "yes" because we are talking about using rangelands to produce

\footnotetext{
'Web site available at http://www.sustainablerangelands.org/pdf/ Ecosystem_Goods_Services.pdf. 
plant materials that can be used as feedstock for biofuels production. Biofuels are important for human well-being to the extent that they can replace other sources of fuels. Many states are passing legislation requiring that a certain percentage of their energy comes from renewable sources, and scientists recently stated that biofuel grasses have the potential to replace corn-based ethanol in a way that is both environmentally and economically beneficial. ${ }^{13}$ University of Illinois and Colorado State University researchers found that using biofuel grass species, such as switchgrass, in the same land area as used to grow corn could result in an increase in ethanol production, a reduction in nitrogen leaching into the Gulf of Mexico, and a reduction in greenhouse gas emission caused from the Corn Belt in the Midwest region of the United States. The research shows that, by replacing corn ethanol, perennial grasses could increase the productivity of food and fuel within the region without causing additional indirect land use change. ${ }^{13}$ The more ambiguous EGS discussions in this example are related to the "Wants" questions.

Does the EGS provide a basic human need? Is it important to society? Although biofuels do not necessarily provide a basic human need, they are deemed to be important to society. Ethanol is being used as a substitute for fossil fuel-based gasoline. They agree to rate this as medium.

What is the current level of demand for the EGS? Demand for ethanol products is increasing and new technologies are being developed to produce it more efficiently and from different feedstocks. With the state-driven legislative mandates, demand for such energy sources can only be expected to increase over the next few decades. They agree to rate this as low-medium.

How responsive is the EGS to management? Once the plant material desired for biofuel production is selected and demonstrated to be cultivated on rangelands, it will be very responsive to management. In discussions about the tradeoffs, the rancher comes to understand that there will be a net loss in other EGS, such as reduced forage and changes in wildlife habitat, erosion potential, or the landowner's viewscape. Each of those would have to be evaluated using this same set of questions. They agree to rate this as high.

How easily is the EGS measured? Measurement of the amount of biofuel feedstock produced is relatively easy, and predicted ranges would become known for this specific area over time. Estimating prices for the feedstock is more uncertain, depending on where a processing facility is built and the number of those that participate in the market. They agree to rate this as high.

How important is the EGS over local, regional, and national spatial scales? Feedstock production and processing is important at the local scale. The location of the processing facility in relation to the ranch is a critical factor in determining whether the alternative is economically feasible. The demand (and hence prices received) for the feedstock are probably more important at the regional and national scales where demand for the final product (ethanol) is set. They agree to rate this as high for local, medium for regional, and medium for national.

How important is the EGS over different temporal scales? Production and demand for the feedstock is expected to increase over time. Demand will be driven by higher crude oil costs and the legislatively driven desire to reduce dependence on fossil fuels. They agree to rate this as medium.

How resilient is the EGS? Once established, the feedstock could be resilient. However, rangelands as a whole will become less resilient due to the loss of biological diversity and alternation from a native, intact system to one that resembles a monoculture. They rate this as low.

How much does human activity impact the EGS? Fuel consumption impacts the demand for feedstock. They rate this as medium.

How important are rangelands to this EGS? National rangelands will probably never produce a significant portion of biofuels compared to what can be produced on crop and forest lands. However, for specific locations, rangelands could produce significant amounts. They agree to rate this as low.

How unique is the EGS to rangelands? Production of feedstocks from rangelands is not unique. They agree to rate this as low.

For this good, are there no potential substitutes? There are numerous alternative sources of biofuel feedstocks from crop and forest lands. They agree to rate this as low.

Is the EGS impacted by local, state, or federal regulations? At this point in time, biofuel feedstock production is not impacted any more or less than any other crop. Regulations on clean air, clean water, product safety, worker safety, etc. affect its production just as any other agricultural production activity. They agree to rate this as low.

Discussion. At the end of the discussion, the rancher and rangeland management consultant enter the agreed-upon responses into the SRR EGS evaluation worksheet." Table 3 shows their responses for biofuels and a few other ecosystem goods and services. The rancher, in consultation with the rangeland management consultant, now must interpret the results and decide how the information can be used in ranch business planning and decisions regarding investing in one activity or another. After the rancher has evaluated all the EGS potentially available on his ranch as well as the trade-offs of selecting different mixes, he can decide how to proceed. The certified rangeland management consultant can provide advice on management and cost options.

The results in Table 3, combined with the landowner's goals, can eliminate some options and highlight others for further examination. This brief example shows a use of the evaluation questions and associated discussions. SRR participants believe it can be used at a variety of other

"Blank worksheets are available from SRR Web site at http:// sustainablerangelands.org. 
decision making and analysis scales in addition to the private property level. Questions might need to be adjusted for the scale at which the evaluation is occurring, but the questions can lead to fairly thorough discussions.

\section{Conclusions}

As societal values for rangeland EGS continue to evolve and environmental markets develop, opportunities for ranchers to add less traditional enterprises such as bird watching or biofuel production to their operations could arise. However, each new opportunity also might be an economic hazard if proper business planning and evaluation are not performed for these potential alternative income sources. Each potential EGS must be quantified and assessed for viability and practicality as a source of alternative income or new enterprise for a ranching operation.

As illustrated with broad categorizations of EGS and evaluation questions, not every ranch operation can capitalize on every EGS if their rangeland resource base can't support it or associated infrastructure is lacking and/or cost prohibitive. Consistent with SRR's mission to promote resource assessment and rangeland sustainability dialogue, it is important to note that planning, evaluation, and communication prior to initiating a new rangeland EGS-based enterprise are keys to success when pursuing these novel endeavors. SRR invites interested ranchers and land managers to apply this question-based framework for evaluation of rangeland EGS potential on their operations and provide us feedback on its usability.

\section{References}

1. Havstad, K. M., D. P. C. Peters, R. Skaggs, J. Brown, B. Bestelmeyer, E. Fredrickson, J. Herrick, and J. Wright. 2007. Ecological services to and from rangelands of the United States. Ecological Economics 61:261-268.

2. Maestas, J. D., R. L. Knight, and W. C. Gilgert. 2003. Cows, vondos, or neither: what's best for rangeland ecosystems? Rangelands 24(6):36-42.

3. Camp, W. G., And T. B. Daugherty. 2004. Managing our natural resources. Albany, NY, USA: Delmar. 448 p.

4. Shields, D. J., I. M. Martin, W. E. Martin, and M. Haefele. 2002. Survey results of the American public's values, objectives, beliefs, and attitudes regarding forests and grasslands. Fort Collins, CO, USA: Rocky Mountain Research Station. RMRS-GTR-95. $111 \mathrm{p}$.

5. Van Tassell, L. W., E. T. Bartlett, and J. E. Mitchell. 2001. Projected use of grazed forages in the United States: 2000 to 2050: a technical document supporting the 2000 USDA Forest Service RPA Assessment. Fort Collins, CO, USA: Rocky Mountain Research Station. General Technical Report RMRSGTR-82. 73 p.

6. Butler, L. D. 1990. Nontraditional uses of rangelands for income producing activities. In: Conference Proceedings: Income Opportunities for the Private Landowner through Management of Natural Resources and Recreational Access. RD No. 740; 9-12 April 1989; Wheeling, WV, USA. Morgantown,
WV, USA: West Virginia University Extension Service and College Park, MD, USA: Cooperative Extension Service, University of Maryland System. p. 122-127.

7. Berger, M. E. 1973. Recreation potential of Texas rangelands. Journal of Range Management 26:92-93.

8. Rowan, R. C., and J. P. Workman. 1992. Factors affecting Utah ranch prices. Journal of Range Management 45:263-266.

9. Maczko, K. A., L. D. Bryant, and D. W. Thompson. 2004. Putting the pieces together: assessing social, ecological, and economic rangeland sustainability. Rangelands 26(3):3-14.

10. Fox, W. E., D. W. McCollum, J. E. Mitchell, L. E. Swanson, G. R. Evans, J. Heintz, H. Theodore, J. A. Tanaka, U. P. Kreuter, R. P. Breckenridge, and P. H. Geissler. 2009. Integrated social, economic and ecological concept (ISEEC) for sustainable rangelands. Society and Natural Resources 22:593-606.

11. Maczko, K., And L. Hidinger [eds.]. 2008. Sustainable rangelands ecosystem goods and services. SRR Monograph No. 3. Sustainable Rangelands Roundtable. Fort Collins, CO, USA: Colorado State University, Warner College of Natural Resources. 111 p.

12. Folke, C., J. E. Duffy, and S. Draggan. 2006. Millennium ecosystem assessment. In: C. J. Cleveland [ED.]. Encyclopedia of Earth. Washington, DC, USA: Environmental Information Coalition, National Council for Science and the Environment. Available at: http://www.eoearth.org/article/Millennium_ Ecosystem_Assessment. Accessed 2 September 2011.

13. Davis, S. C., W. J. Parton, S. J. Del Grosso, C. Keough, E. Marx, P. R. Adler, and E. H. DeLucia. 2011. Impact of second-generation biofuel agriculture on greenhouse-gas emissions in the corn-growing regions of the US. Available at: Frontiers in Ecology and the Environment (e-View) http:// www.esajournals.org/doi/abs/10.1890/110003. Accessed 2 September 2011.

Authors are Deputy Director and Research Scientist, Sustainable Rangelands Roundtable, University of Wyoming, 2150A Centre Ave, Fort Collins, CO 80526, USA, kmaczko@uwyo.edu (Maczko); Department Head, Dept of Renewable Resources, University of Wyoming, 1000 E University Ave, Laramie, WY 82071, USA (Tanaka); Senior Scientist, Idaho National Laboratory, 2525 Fremont Ave, Idaho Falls, ID 83415, USA (Breckenridge); Managing Director, Consortium for Science Policy and Outcomes, Arizona State University, Tempe, AZ 85287, USA (Hidinger); Indicator Coordinator (retired), White House Council on Environmental Quality, 722 Jackson Place NW, Washington, DC 20503, USA (Heintz); Assistant Professor, Texas AgriLife Research, Blackland Research and Extension Center, 720 East Blackland Rd, Temple, TX 76502, USA (Fox); Associate Professor, Ecosystem Science and Management Dept, Texas A\&M University, 2138 TAMU, College Station, TX 77843-2138, USA (Kreuter); Science Programs Director, Ecological Society of America, 1990 M St NW, Suite 700, Washington, DC 20036, USA (Duke); and Rangeland Scientist Emeritus (Mitchell) and Economist (McCollum), USDA Forest Service, Rocky Mountain Research Station, 2150A Centre Ave, Fort Collins, CO 80526, USA. 